\title{
Complexo Acinetobacter calcoaceticus - Acinetobacter baumannii (ACB): ocorrência e perfil de resistência aos carbapenêmicos e polimixina B durante pandemia de SARS-
}

\section{CoV-2 em Pelotas, RS}

\author{
Acinetobacter calcoaceticus - Acinetobacter baumannii (ACB) complex: occurrence and profile of \\ resistance to carbapenems and polymixin B during SARS-CoV-2 pandemic in Pelotas, RS \\ Complejo Acinetobacter calcoaceticus - Acinetobacter baumannii (ACB): ocurrencia y perfil de \\ resistencia a carbapenemes y polimixina B durante la pandemia de SARS-CoV-2 en Pelotas, RS
}

Luiza Oliveira Lemos Miller

ORCID: https://orcid.org/0000-0003-3530-1578 Universidade Federal de Pelotas, Brasil E-mail: luizamiller42@gmail.com

Luiza de Souza Kern

ORCID: https://orcid.org/0000-0001-9982-0401 Universidade Federal de Pelotas, Brasil E-mail: luizakern@gmail.com

Róger Giusti Miller

ORCID: https://orcid.org/0000-0002-6432-6240 Universidade Federal de Pelotas, Brasil E-mail: giustimiller9@gmail.com

Camila De David Tessele Martini ORCID: https://orcid.org/0000-0002-3605-1294 Universidade Federal de Pelotas, Brasil E-mail: camilatessele@hotmail.com Marta Pinho da Rosa ORCID: https://orcid.org/0000-0001-8933-0572 Universidade Federal de Pelotas, Brasil E-mail: marta.rosa@ebserh.gov.br

Daiane Drawanz Hartwig

ORCID: https://orcid.org/0000-0003-3604-0832 Universidade Federal de Pelotas, Brasil E-mail: daianehartwig@gmail.com

\begin{abstract}
Resumo
Bactérias do complexo Acinetobacter calcoaceticus - Acinetobacter baumannii (ACB) são causa frequente das chamadas Infecções Relacionadas à Assistência à Saúde (IRAS). Durante a pandemia de COVID-19, causada pelo vírus SARS-CoV-2, coinfecções e aumento da resistência bacteriana aos antibióticos têm sido observados. Assim, o presente estudo verificou a ocorrência e perfil de resistência aos carbapenêmicos (no ano de 2020) e a polimixina B (de outubro de 2020 a março de 2021) em bactérias do complexo ACB, durante a pandemia de SARS-CoV-2, no Hospital Escola (HE) da Universidade Federal de Pelotas (UFPel/EBSERH). Duas metodologias foram aplicadas, a de identificação e avaliação da suscetibilidade bacteriana por automação (BD Phoenix ${ }^{\mathrm{TM}}$ ), e avaliação da resistência a polimixina B utilizando painel de microdiluição (CIM POLIMIXINA B, Laborclin). Oitenta e um isolados pertencentes ao complexo ACB foram identificados, sendo 69,1\% (56) da espécie A. baumannii e 30,9\% (25) de outras espécies do complexo ACB. Foi observado um aumento da resistência aos carbapenêmicos de $75 \%$ em 2019, para 94,3\% em 2020. Dentre as bactérias do complexo ACB resistentes aos carbapenêmicos, 4 delas foram resistentes também a polimixina B. As bactérias do complexo ACB resistentes aos carbapenêmicos foram mais frequentes na UTI COVID-19, representando 44,9\% em relação as outras unidades. Esses isolados resistentes foram obtidos de amostras de aspirado traqueal e sangue. Os dados obtidos revelam um aumento da resistência aos carbapenêmicos, além de uma maior frequência de bactérias do complexo ACB obtidas de aspirado traqueal de pacientes diagnosticados com COVID-19, o que pode estar relacionado a quadros de Pneumonia Associada a Ventilação Mecânica (PAVM).
\end{abstract}

Palavras-chave: IRAS; Resistência antimicrobiana; COVID-19; Coinfecções bacterianas. 


\begin{abstract}
Bacteria of the Acinetobacter calcoaceticus - Acinetobacter baumannii (ACB) complex are a frequent cause of the socalled Healthcare-Associated Infections (HAI). During the COVID-19 pandemic, caused by the SARS-CoV-2 virus, coinfections and increased bacterial resistance to antibiotics have been observed. Thus, the present study verified the occurrence and profile of resistance to carbapenems (in the year 2020) and polymyxin B (from October 2020 to March 2021) in bacteria of the ACB complex during the SARS-CoV-2 pandemic in the Hospital School (HE) of the Federal University of Pelotas (UFPel/EBSERH). Two methodologies were applied, the identification and evaluation of bacterial susceptibility by automation (BD Phoenix ${ }^{\mathrm{TM}}$ ), and the evaluation of resistance to polymyxin B using the microdilution panel (CIM POLYMIXIN B, Laborclin). Eighty-one isolates belonging to the ACB complex were identified, 69.1\% (56) of the species A. baumannii, and 30.9\% (25) of other species of the ACB complex. An increase in resistance to carbapenems from $75 \%$ in 2019 to $94.3 \%$ in 2020 was observed. Among the bacteria of the ACB complex resistant to carbapenems, 4 of them were resistant to polymyxin B. The bacteria of the ACB complex resistant to carbapenems were more frequent in the COVID-19 ICU, representing $44.9 \%$ in relation to other units. These resistant isolates were obtained from tracheal aspirate and blood samples. The data obtained reveal an increase in resistance to carbapenems, in addition to a higher incidence of positive tracheal aspirate for bacteria of the ACB complex in patients diagnosed with COVID-19, which may be related to Pneumonia Associated with Mechanical Ventilation (VAP).
\end{abstract}

Keywords: HAI; Antimicrobial resistance; COVID-19; Bacterial coinfections.

\title{
Resumen
}

Las bacterias del complejo Acinetobacter calcoaceticus - Acinetobacter baumannii (ACB) son una causa frecuente de las llamadas Infecciones Asociadas a la Atención de la Salud (IAAS). Durante la pandemia de COVID-19, causada por el virus SARS-CoV-2, se han observado coinfecciones y una mayor resistencia bacteriana a los antibióticos. Así, el presente estudio verificó la ocurrencia y perfil de resistencia a carbapenémicos (en el año 2020) y polimixina B (de octubre de 2020 a marzo de 2021) en bacterias del complejo ACB durante la pandemia SARS-CoV-2 en el Hospital Escuela (HE) de la Universidad Federal de Pelotas (UFPel/EBSERH). Se aplicaron dos metodologías, la identificación y evaluación de la susceptibilidad bacteriana por automatización (BD Phoenix ${ }^{\mathrm{TM}}$ ), y la evaluación de la resistencia a la polimixina B mediante el panel de microdilución (CIM POLYMIXIN B, Laborclin). Se identificaron 81 bacterias pertenecientes al complejo ACB, 69,1\% (56) de la especie A. baumannii y 30,9\% (25) de otras especies del complejo ACB. Se observó un aumento de la resistencia a los carbapenémicos del 75\% en 2019 al 94,3\% en 2020. Entre las bacterias del complejo ACB resistentes a los carbapenémicos, 4 de ellas eran resistentes a la polimixina B. Las bacterias del complejo ACB resistentes a los carbapenémicos eran más frecuentes en la UCI COVID-19, representando el 44,9\% en relación a otras unidades. Las bacterias resistentes se obtuvieron de aspirado traqueal y muestras de sangre. Los datos obtenidos revelan un aumento de la resistencia a los carbapenémicos, además de una mayor incidencia de aspirado traqueal positivos para bacterias del complejo ACB en pacientes diagnosticados de COVID-19, lo que puede estar relacionado con Neumonía Asociada a Ventilación Mecánica (NAV).

Palabras clave: IAAS; Resistencia antimicrobiana; COVID-19; Coinfecciones bacterianas.

\section{Introdução}

Bactérias do gênero Acinetobacter spp. são cocobacilos Gram-negativos, não fermentadores de glicose, ubíquos, aeróbios, imóveis, não fastidiosos, oxidase negativos e catalase positivos (Bergone-Berezin \& Towner, 1996; Al Atrouni et al., 2016). Quatro espécies deste gênero são semelhantes fenotipicamente, sendo enquadradas no complexo Acinetobacter calcoaceticus - Acinetobacter baumannii (ACB), sendo elas: A. calcoaceticus, A. baumannii, A. nosocomialis e A. pittii (Gerner-Smidt et al., 1991; Nemec et al., 2011). Testes fenotípicos e bioquímicos convencionais utilizados em laboratórios de análises microbiológicas não são capazes de diferenciar com total confiança as espécies do complexo ACB, para isso são necessários testes moleculares. Em relação à identificação de bactérias Gram-negativas, o equipamento de identificação bacteriana automatizado BD Phoenix ${ }^{\mathrm{TM}}$ apresentou em estudo comparativo uma concordância de 95,6\% a nível de espécie e uma discordância de 3,6\% (Bergogne-Bérézin \& Tower, 1996; Peleg et al., 2008; Manual do Operador BD Phoenix System).

Características como capacidade de sobrevivência por longos períodos em superfícies inanimadas no ambiente hospitalar e maior resistência aos antibacterianos fazem com que, dentre as espécies do complexo ACB, A. baumannii seja a mais frequentemente relatada em surtos e Infecções Relacionadas à Assistência à Saúde (IRAS), desta forma é considerada a de maior relevância clínica (Lee et al., 2017; Shamsizadeh et al., 2017; Chapartegui-González et al., 2018; Vázquez-López et al., 2020). 
Os carbapenêmicos são antibióticos de primeira escolha no tratamento de infecções causadas por bactérias Gramnegativas produtoras de $\beta$-lactamases, como a A. baumannii. Entretanto, A. baumannii resistente aos carbapenêmicos, as chamadas cepas Carbapenem-resistant A. baumannii (CRAb), têm sido descritas em infecções hospitalares e surtos ao redor do mundo (Codjoe et al., 2017; Raro et al., 2017; Ramette et al., 2018; Koirala et al., 2020). Quanto às polimixinas, elas são antibióticos de última escolha, utilizadas no caso de cepas multirresistentes, contudo, já existem relatos de resistência a essa classe de antibióticos (Genteluci et al., 2020).

A maior parte dos isolados de A. baumannii obtidos de pacientes internados em instituições hospitalares é advinda do trato respiratório, estando comumente associadas à ventilação mecânica e longos períodos de internação. Dentre as manifestações clínicas de infecção relatadas tem-se: pneumonia adquirida em hospital, pneumonia adquirida pela comunidade, infecção da corrente sanguínea, traumas e feridas de pele, infecções por cateter em pacientes internados em unidades de tratamento intensivo e meningites (Peleg et al., 2008).

As coinfecções bacterianas mostraram-se presentes em pandemias virais, como na pandemia de Influenza de 19181919. Uma análise de relatórios de autópsias, bacteriológicos e histopatológicos demonstrou que a maioria das mortes por Influenza eram, possivelmente, resultantes de pneumonia bacteriana secundária (Morens et al., 2008). Da mesma forma, na pandemia de Influenza em 2009, relacionou-se a pneumonia bacteriana com a letalidade dos casos (Barnes et al., 2019). Em pesquisa realizada na China, onde foram coletadas amostras de escarro de 195 pacientes com pneumonia adquirida na comunidade (PAC), internados no First Affiliated Hospital of Shantou University Medical College, durante epidemia de Influenza de janeiro a agosto de 2016, foi identificada A. baumannii como a bactéria mais frequentes (Lin et al., 2019).

Diante disso, percebe-se a estrita relação entre pandemias virais e coinfecções bacterianas. Ademais, na pandemia da COVID-19, causada pelo SARS-CoV-2, esta relação também vem sendo evidenciada. De fevereiro a julho de 2020 , foi observado aumento das infecções e colonizações por cepas CRAb adquiridas em um hospital de Nova Jersey, destinado ao atendimento de pacientes durante a pandemia de COVID-19. Dos 34 pacientes com infecção ou colonização por CRAb multirresistente, $21(62 \%)$ haviam sido internados em UTIs destinadas a pacientes com COVID-19. Esse aumento do número de infecções por cepas CRAb foi relacionado ao aumento do número de internações por COVID-19, que acabou afetando a dinâmica do hospital, onde faltou pessoal, equipamento de proteção individual (EPI) e equipamento médico, levando a alterações nas práticas convencionais de prevenção e controle de infecção. Com a diminuição do número de internações por COVID-19, o sistema se restabeleceu, voltando com as práticas padrões de prevenção de infecção e assim, posteriormente, o número de casos de CRAb diminuiu (Perez et al, 2020). Outros autores alertam para o aumento da resistência bacteriana durante a pandemia, devido ao uso de antibacterianos no tratamento empírico de pacientes acometidos pela COVID-19 (Cantón et al., 2020; Vaughn et al., 2020; Monnet et al., 2020).

Tendo em vista que bactérias pertencentes ao complexo ACB são recorrentes em IRAS, e há a preocupação com a multirresistência destes agentes infecciosos no ambiente hospitalar, somado à atual situação da pandemia de COVID-19 e ao aumento no número de internações hospitalares, pacientes infectados com SARS-CoV-2 e internados, podem possuir risco elevado de coinfecções por bactérias multirresistentes do complexo ACB. Este tipo de estudo faz-se necessário, para que se possa analisar como as infecções e perfil de resistência das bactérias deste complexo atuaram durante este período. Nesse sentido, o presente estudo teve por objetivo realizar um levantamento da ocorrência e o perfil de resistência aos carbapenêmicos e à polimixina $\mathrm{B}$ de isolados clínicos do complexo $\mathrm{ACB}$ obtidos de pacientes internados no Hospital Escola (HE) da Universidade Federal de Pelotas (UFPel/EBSERH), durante a pandemia de COVID-19, além de verificar em qual unidade do hospital e sítio de infecção se concentram essas bactérias. 


\section{Metodologia}

\subsection{Coleta de dados}

O presente estudo foi conduzido de acordo com a Declaração de Helsinki. Foram obtidos dados retrospectivos a partir do banco de dados do software BD Epicenter ${ }^{\mathrm{TM}}$ do equipamento BD Phoenix ${ }^{\mathrm{TM}}$ (Becton, Dickinson and Company, New Jersey, EUA), utilizado no Laboratório de Análises Clínicas do HE - UFPel/EBSERH. Os relatórios emitidos pelo software forneceram a identificação bacteriana e o perfil de resistência aos antibacterianos, incluindo carbapenêmicos. Estes dados foram categorizados por unidades do hospital, pelo sítio de infecção, e foram liberados pelo equipamento na forma de gráfico de barras e expresso em percentual para análise do perfil de resistência aos carbapenêmicos. Para a análise do perfil de resistência à polimixina $\mathrm{B}$, os resultados foram expressos, em primeiro momento, através de estatística descritiva, sendo tabulados e analisados no Programa Microsoft Excel®. Os relatórios emitidos pelo software não tinham a identificação nominal do paciente e nem foram coletados exclusivamente para a realização da pesquisa. O Termo de Confidencialidade dos Dados foi assinado, sendo dispensado dessa forma, o Termo de Consentimento Livre e Esclarecido (TCLE). Foram utilizados dados como: data, tipo de amostra (aspirado traqueal, hemocultura, urocultura, entre outras), o antibiograma realizado pela instituição e o local de internação do paciente (UTI adulto, UTI COVID-19, clínica COVID-19, RUE - Rede de Urgência e Emergência I, II e III, Equipes Multidisciplinares de Atenção Domiciliar-EMAD, UTI neonatal, clínica médica, clínica cirúrgica e clínica pediátrica). Exemplo: Data/Paciente 01 (anônimo)/Amostra 01/AT/UTI.

A população deste estudo foi constituída por todos os pacientes que tiveram culturas positivas para bactérias do complexo ACB, no período de janeiro a dezembro de 2020, para avaliar o perfil de resistência aos carbapenêmicos, e de outubro de 2020 a março de 2021 para avaliar o perfil de resistência à polimixina B. Foram excluídos pacientes que não tiveram exame microbiológico solicitado, em que não houve o crescimento bacteriano em culturas solicitadas ou com resultado positivo para outros micro-organismos. O presente estudo foi submetido e aprovado pelo Comitê de Ética em Pesquisa da Universidade Federal de Pelotas, n. 4.570.419, de acordo com a Resolução nº 466/2012 do Conselho Nacional de Saúde.

\subsection{Identificação bacteriana e testes de sensibilidade}

A identificação bacteriana foi feita por meio dos testes bioquímicos convencionais cromogênicos e fluorogênicos, utilizando o sistema automatizado BD Phoenix ${ }^{\text {TM }}$ (Becton, Dickinson and Company, New Jersey, EUA). Para identificação e testes de sensibilidade da maioria das bactérias Gram-negativas, como as bactérias do complexo ACB, em amostras de urina foi utilizado o painel UNMIC/ID-407 (Becton, Dickinson and Company, New Jersey, EUA) e para as demais amostras foi utilizado o painel NMIC/ID-406 (Becton, Dickinson and Company, New Jersey, EUA). O painel UNMIC/ID-407 inclui testes de suscetibilidade aos seguintes antibacterianos: Amicacina, Amoxicilina/Clavulanato, Cefazolina, Cefepima, Cefoxitina, Ceftazidima, Ceftriaxona, Cefuroxima, Ciprofloxacina, Ertapenem, Gentamicina, Imipenem, Levofloxacino, Meropenem, Nitrofurantoína, Norfloxacina, Piperacilina/Tazobactam, Tetraciclina, Trimetropim/Sulfametoxazol, Cefotaxima/Clavulanato (ESBL), Ceftazidima/Clavulanato (ESBL), Cefpodoxima-Proxetil (ESBL), Ceftazidima (ESBL), Ceftriaxona/Clavulanato (ESBL). Já o painel NMIC/ID-406 possui ainda Fosfomicina e Tigeciclina, e não possui Nitrofurantoína e Norfloxacina. A identificação bacteriana e os testes de sensibilidade seguiram de acordo com o preconizado pelo Clinical and Laboratory Standards Institute (CLSI).

\subsection{Perfil de sensibilidade à polimixina $B$}

Para determinação do perfil de sensibilidade a polimixina B foi utilizado o painel de microdiluição CIM POLIMIXINA B (Laborclin, Vargem Grande, Brasil), destinado à determinação da Concentração Inibitória Mínima (CIM) de polimixina B para bacilos Gram-negativos, como as bactérias do complexo ACB, conforme metodologia preconizada pelo 
Clinical and Laboratory Standards Institute (CLSI) e European Committee or Antimicorbial Susceptibility Testing (EUCAST/BRcast). Para este ensaio é preparado o inóculo bacteriano em uma concentração final de $5 \times 10^{5} \mathrm{UFC} / \mathrm{mL}$, essa suspensão é transferida na quantidade de $100 \mu \mathrm{L}$ para cada cavidade do painel, primeiramente para a cavidade do controle de crescimento (CC), e depois sempre da menor concentração $(0,125 \mu \mathrm{g} / \mathrm{mL})$ para maior concentração $(32 \mu \mathrm{g} / \mathrm{mL})$. A incubação é feita a $35^{\circ} \mathrm{C}$ em câmara úmida por 18-20 h. Após esse período, a leitura é realizada contra a luz, pela observação de precipitado de bactérias no fundo da cavidade e/ou da turvação do meio e o resultado é liberado em $\mu \mathrm{g} / \mathrm{mL}$. A técnica de microdiluição é padrão ouro para disponibilizar resultados quantitativos, fornecendo a mínima concentração necessária do antibacteriano in vitro para inibir o crescimento da bactéria. Para o controle de qualidade desta técnica utilizam-se cepas padrão: ATCC® (American Type Culture Collection) ou derivadas. Para cepa de Escherichia coli ATCC® 25922 o resultado esperado é de 0,25-2 $\mu \mathrm{g} / \mathrm{mL}$ e para Pseudomonas aeruginosa ATCC® 27853 o resultado esperado é de 0,5-2 $\mu \mathrm{g} / \mathrm{mL}$.

\section{Resultados e Discussão}

De janeiro a dezembro de 2020, no Laboratório de Análises Clínicas do HE - UFPel/EBSERH, através do método de identificação bacteriana utilizando equipamento automatizado BD Phoenix ${ }^{\mathrm{TM}}$, foram identificados 81 isolados bacterianos pertencentes ao complexo ACB, 69,1\% (56) destes identificados como A. baumannii e 30,9\% (25) identificados como outras espécies do complexo ACB. Para os resultados do perfil de resistência, o equipamento disponibiliza a média ponderada entre os valores de resistência de bactérias do complexo ACB e A. baumannii, enquadrando A. baumannii dentro do complexo. Em 2019, no mesmo hospital, de acordo com os relatórios da Comissão de Controle de Infecção Hospitalar (CCIH), o número de isolados pertencentes ao complexo ACB identificados foi de 36, sendo 31 (86,1\%) deles da espécie A. baumanii, e os demais $(\mathrm{n}=5,13,9 \%)$ das outras espécies que compõem o complexo. O aumento no número de isolados do complexo ACB, especialmente A. baumannii é um fator preocupante, sendo evidenciado comparando períodos durante e anteriores à pandemia. Dados do Laboratório Central do Estado do Paraná (LACEN-PR) demonstraram um aumento de 130\% dos isolados, comparando os primeiros trimestres de 2019 e de 2021 (ANVISA, 2021).

Quanto ao perfil de resistência aos antibióticos, as bactérias do complexo ACB incluídas no presente estudo apresentaram 100\% de resistência à Amoxicilina-Clavulanato, Ampicilina, Cefazolina, Cefoxitina, Ceftriaxona, Cefuroxima, Fosfomicina com G6P, Nitrofurantoína, Norfloxacina, Tetraciclina e Tigeciclina; 96,2\% de resistência à Cefepima e Piperacilina-Tazobactam; 95\% a Meropenem, Levofloxacino e Ciprofloxacino; 93,7\% ao Imipenem, TrimetropimSulfametoxazol, Gentamicina e Ceftazidima; 93,5\% a Ampicilina-Sulbactam e 90\% à Amicacina (Figura 1).

Em pesquisa feita com isolados do complexo ACB obtidos de aspirados traqueais de pacientes internados na UTI do HU-UNIVASF/EBSERH, no período de janeiro a junho de 2018, foram observados valores menores de resistência ao Imipenem (77\%), Meropenem (79\%), Ciprofloxacino (83\%), Cefepima (82\%) Piperacilina-Tazobactam (80\%), Levofloxacino (81\%), Ceftazidima (77\%), Gentamicina (51\%), Ampicilina-Sulbactam (48\%) e Tetraciclina (40\%). Enquanto a Ceftriaxona e a Ampicilina apresentaram a mesma porcentagem de resistência (100\%) comparando com o presente estudo (Ribeiro et al., 2019). 
Figura 1 - Porcentagem de resistência $(\% \mathrm{R})$ aos antibióticos em culturas positivas de bactérias do complexo ACB obtidas de pacientes internados no HE-UFPel, no ano de 2020.

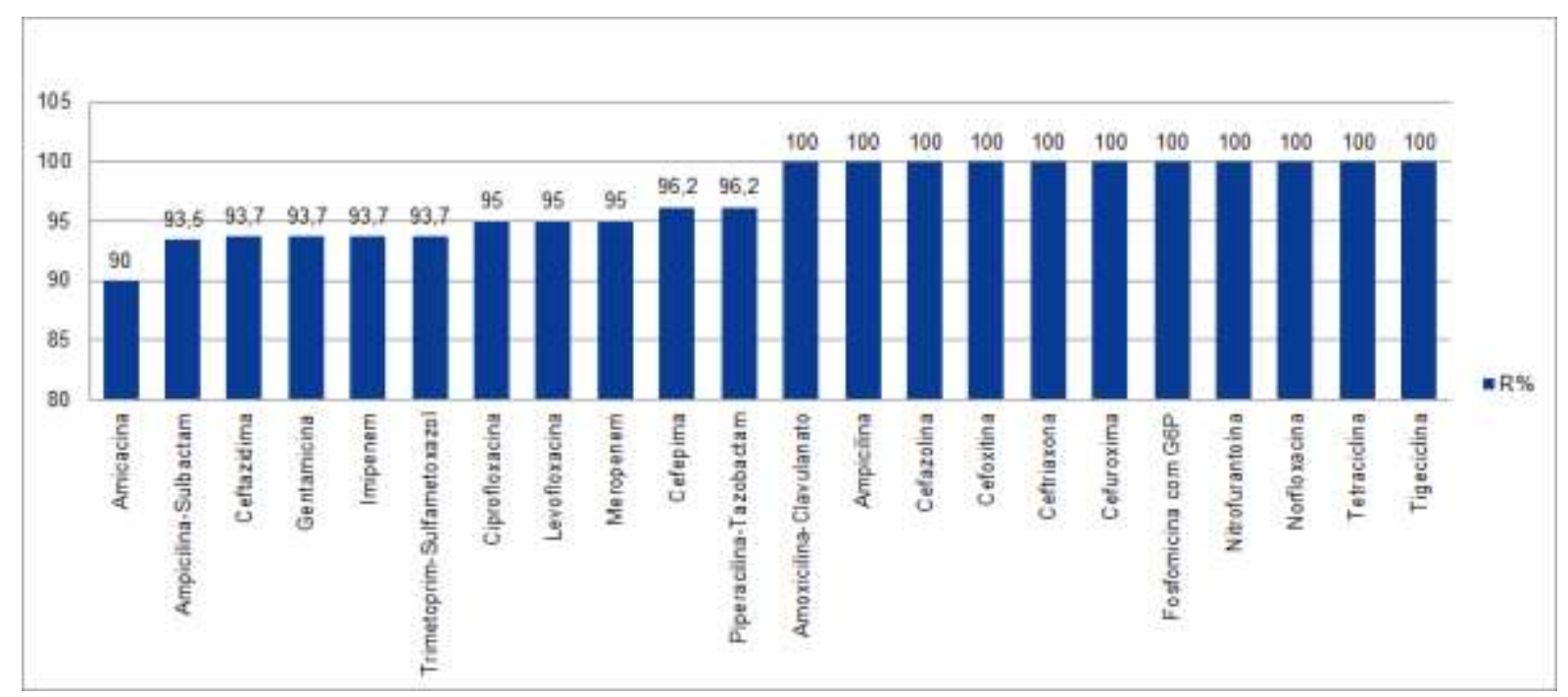

Fonte: Autores (2021).

Dados do LACEN-PR mostraram que quase $100 \%$ dos isolados de A. baumannii são resistentes aos carbapenêmicos (ANVISA, 2021). Este aumento da resistência aos carbapenêmicos foi observado no presente estudo, em comparação com dados de 2019 do mesmo hospital. Neste ano, isolados de A. baumannii apresentaram 75\% de resistência aos carbapenêmicos, enquanto em 2020 subiu para 94,3\%. Da mesma forma, um aumento de cepas CRAB têm sido descritas por outros autores durante a pandemia (Gaspar et al., 2020; Perez et al., 2020; Gottesman et al., 2021; Shinohara et al., 2021).

Como rotina, para isolados do complexo ACB resistentes aos carbapenêmicos e a todos os outros antibacterianos, é feito o teste de Concentração Inibitória Mínima (CIM) para polimixina B, que seria a última alternativa antibiótica para tratamento. Nestes casos, em nosso estudo, de outubro de 2020 a março de 2021, um total de 49 isolados resistentes a carbapenêmicos foram reportados, e destes, 4 (8,2\%) foram resistentes à polimixina B, enquanto 45 (91,8\%) foram intermediárias (Tabela 1).

Tabela 1 - Concentração Inibitória Mínima (CIM) de polimixina B para os 49 isolados do complexo ACB obtidos de pacientes internados no HE-UFPel/EBSERH, de outubro de 2020 a março de 2021.

\begin{tabular}{c|c|c}
\hline & \multicolumn{2}{c}{ CIM $(\mu \mathrm{g} / \mathrm{mL})$} \\
\hline & Resistente & Intermediário \\
\hline polimixina B & $\geq 4$ & $\leq 2$ \\
\hline $\mathrm{n}^{\mathrm{o}}$ de isolados & 4 & 45 \\
\hline$\%$ de isolados & 8,2 & 91,8 \\
\hline \multicolumn{3}{c}{ Fonte: Autores (2021). }
\end{tabular}

O aumento do uso das polimixinas acarretou uma maior taxa de resistência de bactérias Gram-negativas, incluindo $A$. baumannii (Li et al., 2019). Esse aumento da resistência foi evidenciado durante a pandemia de COVID-19, onde dados do 
LACEN (PR) demonstraram que o percentual de resistência à polimixina aumentou em 20\% em 2021 (ANVISA, 2021). No presente estudo, quatro isolados obtidos de amostras de sangue e aspirado traqueal, foram resistentes à polimixina $\mathrm{B}$, sendo dois deles obtidos de pacientes internados na UTI COVID-19, apresentando uma CIM=4 $\mu \mathrm{g} / \mathrm{mL}$. Os outros dois isolados resistentes a polimixina B foram obtidos de pacientes internados na clínica COVID-19 (amostra de sangue) e clínica médica (swab de ferida operatória), os quais apresentaram $\mathrm{CIM}=8 \mu \mathrm{g} / \mathrm{mL}$. Portanto, dos quatro isolados resistentes a polimixina B, três eram de unidades destinadas a pacientes diagnosticados com COVID-19, sendo a maior CIM para polimixina B observada nas clínicas COVID-19 e médica. (Tabela 2).

Tabela 2 - Perfil de susceptibilidade a polimixina B dos 49 isolados do complexo ACB resistentes aos carbapenêmicos, obtidos de pacientes internados no HE-UFPel/EBSERH, de outubro de 2020 a março de 2021.

\begin{tabular}{c|c|c|c}
\hline Unidade hospitalar & Tipo de amostra & $\begin{array}{c}\text { Número de isolados } \\
\text { resistentes a polimixina B }\end{array}$ & $\begin{array}{c}\text { Resultado da } \\
\mathrm{CIM}(\mu \mathrm{g} / \mathrm{mL})\end{array}$ \\
\hline \multirow{2}{*}{ UTI COVID-19 } & Sangue & 1 & 4 \\
\cline { 2 - 4 } & Aspirado traqueal & 1 & 4 \\
\hline Clínica COVID-19 & Sangue & 1 & 8 \\
\hline Clínica médica & $\begin{array}{c}\text { Swab de ferida } \\
\text { operatória }\end{array}$ & 1 & 8 \\
\hline \multicolumn{2}{|c}{ Fonte: Autores (2021). }
\end{tabular}

Do total de 49 amostras resistentes aos carbapenêmicos e outros antibacterianos, 44,9\% eram da UTI COVID-19, seguido de 34,7\% da UTI adulto, 6,1\% da cirurgia, 4,1\% na clínica COVID-19, 4,1\% na RUE I e 2\% no EMAD II (Figura 2).

Figura 2 - Porcentagem (\%) de isolados de bactérias do complexo ACB resistentes aos carbapenêmicos em diferentes unidades hospitalares.

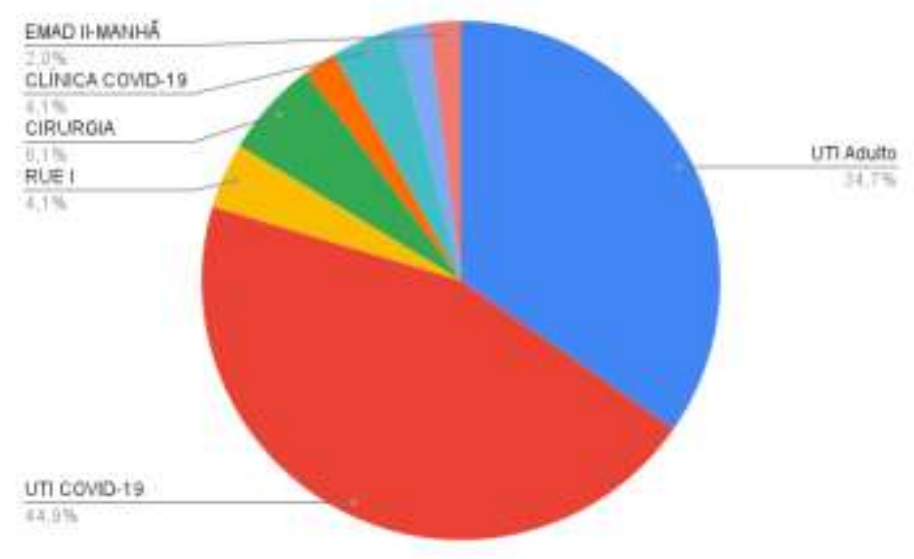

Fonte: Autores (2021).

Como visto, a maior incidência de bactérias do complexo ACB resistentes aos carbapenêmicos foi na UTI COVID-19, seguida da UTI adulto. Uma maior incidência nas UTIs pode ser explicada por alguns fatores: primeiramente, a condição de saúde debilitada dos pacientes internados nessas unidades, que podem passar por um número maior de procedimentos invasivos, além do uso de antibioticoterapia de amplo espectro. Outro fator seria o ambiente e as fontes de transmissão, na 
literatura há vários relatos de surtos relacionados à transmissão por fontes como: válvulas e umidificadores de ventiladores mecânicos, termômetros, luvas, fluxômetros, nutrição parenteral, mãos, nebulizadores de grande volume, travesseiros, entre outros (Raro et al., 2017, Chapartegui-González et al., 2018).

A pandemia de COVID-19 aumentou o número de internações, o que pode ter potencializado a incidência de IRAS. Por outro lado, relata-se que a intensificação das medidas de biossegurança pode ter colaborado para o controle destas infecções. Entretanto, a chegada da COVID-19 alterou a dinâmica de trabalho nos hospitais o que pode ter levado a alterações nas práticas convencionais de prevenção e controle de infecção. Desta forma, ressalta-se a relevância da CCIH para o controle das fontes de transmissão ambiental e pessoal (Gon et al., 2020; Perez et al., 2020; Fram et al., 2021).

Dos isolados de bactérias do complexo ACB resistentes aos carbapenêmicos e outros antibacterianos, 23 (46,9\%) estavam presentes em amostras de aspirado traqueal, 14 (28,6\%) eram de sangue, $4(8,2 \%)$ de escarro, $3(6,1 \%)$ de urina, 2 $(4,1 \%)$ de $s w a b$ de ferida operatória, $1(2 \%)$ de ponta de cateter jugular interno, $1(2 \%)$ de $s w a b$ nasal e $1(2 \%)$ de $s w a b$ anal (Figura 3).

Figura 3 - Ocorrência de bactérias do complexo ACB resistentes a carbapenêmicos por sítio de amostra, de outubro de 2020 a março de 2021.

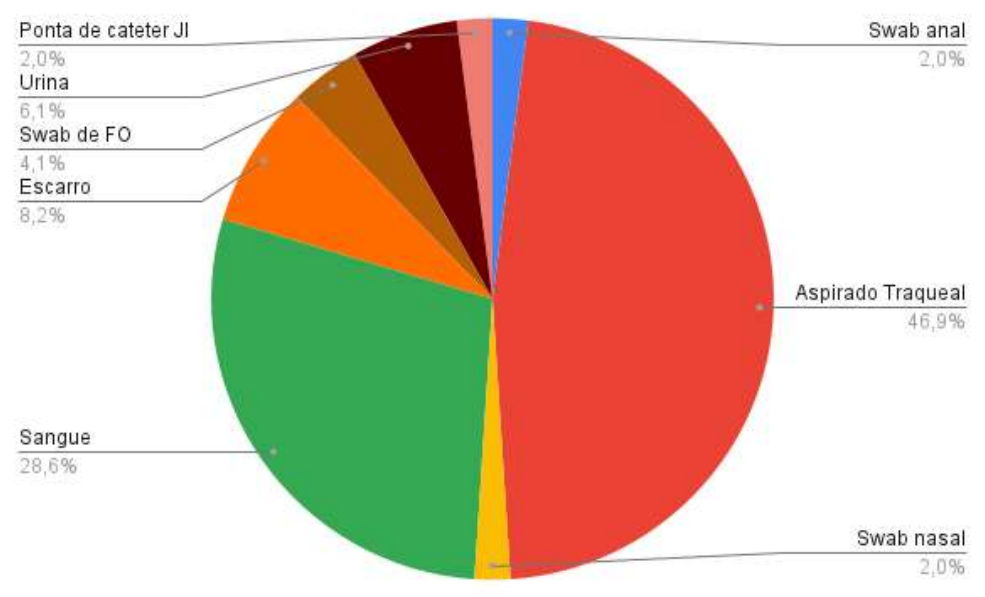

Fonte: Autores (2021).

Foi possível evidenciar uma maior porcentagem de amostras positivas para bactérias do complexo ACB obtidas de aspirado traqueal, representando quase a metade do número total de amostras resistentes aos carbapenêmicos. Ademais, das 23 amostras de aspirado traqueal, 15 eram provenientes da UTI COVID-19 e 8 da UTI adulto. Isso pode ser explicado pelo fato de que o aspirado traqueal é um tipo de amostra coletada para confirmação microbiológica de Pneumonia Associada à Ventilação Mecânica (PAVM), e A. baumannii é um dos patógenos mais relatados nesse tipo de pneumonia. Além disso, correlaciona-se a PAVM com pacientes acometidos pela COVID-19, em estudo retrospectivo de coorte realizado em um hospital público do município de Campina Grande/PB com amostra composta por pacientes diagnosticados com COVID-19 e que necessitam de ventilação mecânica, a maior porcentagem de agentes infecciosos obtidos em amostras de aspirado traqueal foi de Acinetobacter spp. (de Oliveira Sá et al., 2020). Inclusive, cepas Crab foram relatadas em um surto no Hospital Hasharon no centro de Israel, e associadas o maior risco de infecção por estas cepas a pacientes ventilados mecanicamente (Gottesman et al., 2021).

O segundo maior percentual encontrado no presente estudo, de tipo de amostra contendo bactérias do complexo ACB resistentes aos carbapenêmicos, foi de sangue, sendo que das 14 amostras, 6 (42,9\%) eram da UTI COVID-19. Durante a pandemia, as infecções secundárias de corrente sanguínea se mostraram presentes em pacientes diagnosticados com COVID- 
19, como mostrado em estudo realizado de $1^{\circ}$ de março de 2020 a 7 de maio de 2020 , em três centros médicos acadêmicos em Nova Jersey, EUA, com um total de 375 pacientes hospitalizados incluídos com diagnóstico de COVID-19, destes, 128 apresentaram infecções secundárias de corrente sanguínea durante a hospitalização. Para o primeiro conjunto de hemoculturas positivas, $117(91,4 \%)$ eram bacterianas. Em outro estudo, infecções secundárias da corrente sanguínea foram descritas em pacientes hospitalizados com COVID-19 no Hospital IRCCS San Raffaele entre 25 de fevereiro e 6 de abril de 2020, dentre as bactérias Gram-negativas, A. baumannii representou 30,4\% dos isolados, demonstrando ser predominante (Bhatt et al., 2019; Ripa et al., 2020).

\section{Conclusão}

Com o presente estudo foi possível verificar que a frequência de bactérias do complexo ACB aumentou de 36 isolados no ano de 2019, para 81 no ano de 2020. Da mesma forma, houve um aumento da resistência aos carbapenêmicos que passou de 75\% em 2019 para 94,3\% em 2020. Em relação à resistência à polimixina B, foram encontrados 4 isolados resistentes. Uma maior incidência de bactérias do complexo ACB resistentes aos carbapenêmicos foi verificada na UTI COVID-19, seguida da UTI adulto, isso pode ser explicado pela condição de saúde dos pacientes internados nessas unidades incluindo o uso de antibioticoterapia de amplo espectro e a transmissão no ambiente. Ressalta-se que, a pandemia de COVID-19, com o elevado número de internações pode ter acentuado a incidência de IRAS, contudo uma intensificação das medidas de biossegurança pode ter colaborado para o controle destas infecções. Desta forma, evidencia-se a importância do CCIH para o manejo da transmissão ambiental e pessoal, bem como, controle da prescrição empírica de antibióticos de amplo espectro nestes pacientes, uma vez que deve ser priorizado o uso racional baseado em evidências. Além disso, estudos futuros são necessários, incluindo a caracterização genética e fenotípica das bactérias do complexo ACB, que infectam pacientes acometidos pela COVID-19, para uma melhor compreensão do perfil de virulência e resistência destas bactérias.

\section{Agradecimentos}

Agradecemos ao Laboratório de Análises Clínicas e à Comissão de Controle de Infecção Hospitalar (CCIH) do Hospital Escola da Universidade Federal de Pelotas (UFPel/EBSERH) pelo fornecimento dos dados.

\section{Referências}

Anvisa. Nota Técnica GVIMS/GGTES/ANVISA Nº 05/2021. Orientações para prevenção e controle da disseminação de microrganismos multirresistentes em serviços de saúde no contexto da pandemia da COVID-19 - 02/08/2021. https://www.gov.br/anvisa/ptbr/centraisdeconteudo/publicacoes/servicosdesaude/notas-tecnicas/nota-tecnica-gvims-ggtes-anvisa-no-05-2021-resistencia-microbiana-na-pandemia-dacovid-19.

Barnes, C. E., \& MacIntyre, C. R. (2019). Risk modelling the mortality impact of antimicrobial resistance in secondary pneumococcal pneumonia infections during the 2009 influenza pandemic. International Journal of Infectious Diseases: IJID: Official Publication of the International Society for Infectious Diseases, 85, 1-6. https://doi.org/10.1016/j.ijid.2019.05.005

Bergogne-Bérézin, E., \& Towner, K. J. (1996). Acinetobacter spp. as nosocomial pathogens: microbiological, clinical, and epidemiological features. Clinical Microbiology Reviews, 9(2), 148-165. https://doi.org/10.1128/CMR.9.2.148

Bhatt, P. J., Shiau, S., Brunetti, L., Xie, Y., Solanki, K., Khalid, S., Mohayya, S., Au, P. H., Pham, C., Uprety, P., Nahass, R., \& Narayanan, N. (2021). Risk Factors and Outcomes of Hospitalized Patients With Severe Coronavirus Disease 2019 (COVID-19) and Secondary Bloodstream Infections: A Multicenter Case-Control Study. Clinical Infectious Diseases: an official publication of the Infectious Diseases Society of America, 72(12), e995-e1003. https://doi.org/10.1093/cid/ciaa1748

Cantón, R., Gijón, D., \& Ruiz-Garbajosa, P. (2020). Antimicrobial resistance in ICUs: an update in the light of the COVID-19 pandemic. Current Opinion in Critical Care, 26(5), 433-441. https://doi.org/10.1097/MCC.0000000000000755

Chapartegui-González, I., Lázaro-Díez, M., Bravo, Z., Navas, J., Icardo, J. M., \& Ramos-Vivas, J. (2018). Acinetobacter baumannii maintains its virulence after long-time starvation. Plos One, 13(8), e0201961. https://doi.org/10.1371/journal.pone.0201961

Codjoe, F. S., \& Donkor, E. S. (2017). Carbapenem Resistance: A Review. Medical sciences (Basel, Switzerland), 6(1), 1. https://doi.org/10.3390/medsci6010001 
Oliveira Sá, P. K., Silva, S. A., Araújo, C., Cavalca, G., Lira, C., Silva, E., Leite, I. R., Nunes, M., \& Nóbrega, R. (2021). Pneumonia associada à ventilação mecânica em pacientes com COVID-19: avaliação das culturas de aspirados traqueais. The Brazilian Journal of Infectious Diseases, 25, 101089. https://doi.org/10.1016/j.bjid.2020.101089

DME, Diagnósticos Microbiológicos Especializados. Antibiograma das zonas de inibição e concentração inibitória mínima, CLSI 2021. https://www.dme.ind.br/wp-content/uploads/Bula-de-Bancada-CLSI-Edicao-2021.pdf

Fram, D. S., Ferreira, D. B., Matias, L., Coelho, W. E., Escudero, D. V., Antonelli, T. S., \& Medeiros, E. A. (2021). Perfil Epidemiológico das IRAS notificadas em um hospital universitário durante a pandemia da COVID-19. The Brazilian Journal of Infectious Diseases, 25 , 101063. https://doi.org/10.1016/j.bjid.2020.101063

Gaspar, G. G., Bollela, V. R., \& Martinez, R. (2021). Incidência de infecções relacionadas à saúde e perfil de sensibilidade de Staphylococcus aureus, Klebsiella pneumoniae e Acinetobacter baumannii no período pré e durante a pandemia de Covid-19 em unidade de terapia intensiva adulto. The Brazilian Journal of Infectious Diseases, 25, 101062. https://doi.org/10.1016/j.bjid.2020.101062

Genteluci, G. L., de Souza, P. A., Gomes, D., Sousa, V. S., de Souza, M. J., Abib, J., de Castro, E., Rangel, K., \& Villas Bôas, M. (2020). Polymyxin B Heteroresistance and Adaptive Resistance in Multidrug- and Extremely Drug-Resistant Acinetobacter baumannii. Current Microbiology, 77(9), 2300-2306. https://doi.org/10.1007/s00284-020-02064-6

Gerner-Smidt, P., Tjernberg, I., \& Ursing, J. (1991). Reliability of phenotypic tests for identification of Acinetobacter species. Journal of Clinical Microbiology, 29(2), 277-282. https://doi.org/10.1128/jcm.29.2.277-282.1991

Gon, G., Dancer, S., Dreibelbis, R., Graham, W. J., \& Kilpatrick, C. (2020). Reducing hand recontamination of healthcare workers during COVID-19. Infection Control and Hospital Epidemiology, 41(7), 870-871. https://doi.org/10.1017/ice.2020.111

Gottesman, T., Fedorowsky, R., Yerushalmi, R., Lellouche, J., \& Nutman, A. (2021). An outbreak of carbapenem-resistant Acinetobacter baumannii in a COVID-19 dedicated hospital. Infection Prevention in Practice, 3(1), 100113. https://doi.org/10.1016/j.infpip.2021.100113

Kern, L. Hartwig, D.D.H. (no prelo). Ocorrência de bactérias do grupo ESKAPE, perfil de susceptibilidade aos antimicrobianos e relação com infecções relacionadas à assistência em saúde (IRAS) em um hospital de ensino de Pelotas, RS, Brasil.

Koirala, J., Tyagi, I., Guntupalli, L., Koirala, S., Chapagain, U., Quarshie, C., Akram, S., Sundareshan, V., Koirala, S., Lawhorn, J., Doi, Y., \& Olson, M. (2020). OXA-23 and OXA-40 producing carbapenem-resistant Acinetobacter baumannii in Central Illinois. Diagnostic Microbiology and Infectious Disease, 97(1), 114999. https://doi.org/10.1016/j.diagmicrobio.2020.114999

Lee, C. R., Lee, J. H., Park, M., Park, K. S., Bae, I. K., Kim, Y. B., Cha, C. J., Jeong, B. C., \& Lee, S. H. (2017). Biology of Acinetobacter baumannii: Pathogenesis, Antibiotic Resistance Mechanisms, and Prospective Treatment Options. Frontiers in Cellular and Infection Microbiology, 7, 55. https://doi.org/10.3389/fcimb.2017.00055

Li, Z., Cao, Y., Yi, L., Liu, J. H., \& Yang, Q. (2019). Emergent Polymyxin Resistance: End of an Era?. Open Forum Infectious Diseases, 6(10), ofz368. https://doi.org/10.1093/ofid/ofz368

Lin, C., Chen, H., He, P., Li, Y., Ke, C., \& Jiao, X. (2019). Etiology and characteristics of community-acquired pneumonia in an influenza epidemic period. Comparative Immunology, Microbiology and Infectious Diseases, 64, 153-158. https://doi.org/10.1016/j.cimid.2019.03.004

Manual do operador BD Phoenix System. Fabricado por: da Becton, Dickinson and Company. Registrado por: Becton Dickinson Industrias Cirúrgicas Ltda.

Monnet, D. L., \& Harbarth, S. (2020). Will coronavirus disease (COVID-19) have an impact on antimicrobial resistance? Euro Surveillance: Bulletin Europeen Sur Les Maladies Transmissibles = European Communicable Disease Bulletin, 25(45), 2001886. https://doi.org/10.2807/15607917.ES.2020.25.45.2001886

Morens, D. M., Taubenberger, J. K., \& Fauci, A. S. (2008). Predominant role of bacterial pneumonia as a cause of death in pandemic influenza: implications for pandemic influenza preparedness. The Journal of Infectious Diseases, 198(7), 962-970. https://doi.org/10.1086/591708

Nemec, A., Krizova, L., Maixnerova, M., van der Reijden, T. J., Deschaght, P., Passet, V., Vaneechoutte, M., Brisse, S., \& Dijkshoorn, L. (2011). Genotypic and phenotypic characterization of the Acinetobacter calcoaceticus-Acinetobacter baumannii complex with the proposal of Acinetobacter pittii sp. nov. (formerly Acinetobacter genomic species 3) and Acinetobacter nosocomialis sp. nov. (formerly Acinetobacter genomic species 13TU). Research in Microbiology, 162(4), 393-404. https://doi.org/10.1016/j.resmic.2011.02.006

Peleg, A. Y., Seifert, H., \& Paterson, D. L. (2008). Acinetobacter baumannii: emergence of a successful pathogen. Clinical Microbiology Reviews, 21(3), 538582. https://doi.org/10.1128/CMR.00058-07

Perez, S., Innes, G. K., Walters, M. S., Mehr, J., Arias, J., Greeley, R., \& Chew, D. (2020). Increase in Hospital-Acquired Carbapenem-Resistant Acinetobacter baumannii Infection and Colonization in an Acute Care Hospital During a Surge in COVID-19 Admissions - New Jersey, February-July 2020. MMWR. Morbidity and Mortality Weekly Report, 69(48), 1827-1831. https://doi.org/10.15585/mmwr.mm6948e1

Ramette, A., Kronenberg, A., \& the Swiss Centre for Antibiotic Resistance (ANRESIS) (2018). Prevalence of carbapenem-resistant Acinetobacter baumannii from 2005 to 2016 in Switzerland. BMC Infectious Diseases, 18(1), 159. https://doi.org/10.1186/s12879-018-3061-5

Raro, O. H. F., Gallo, S. W., Ferreira, C. A. S., \& Oliveira, S. D. D. (2017). Carbapenem-resistant Acinetobacter baumannii contamination in an intensive care unit. Revista da Sociedade Brasileira de Medicina Tropical, 50, 167-172. https://doi.org/10.1590/0037-8682-0329-2016

Ribeiro, T. D. S., Ribeiro, R. A. A. D. S., Batista, K. S., Aquino, S. R. D., \& Naue, C. R. (2019). Ocorrência e perfil bacteriano de culturas coletadas em pacientes internados na unidade de terapia intensiva em um hospital terciário. HU rev, 122-133. https://doi.org/10.34019/1982-8047.2019.v45.25933 
Ripa M et al. \& COVID-BioB study group (2021). Secondary infections in patients hospitalized with COVID-19: incidence and predictive factors. Clinical Microbiology and Infection: the official publication of the European Society of Clinical Microbiology and Infectious Diseases, 27(3), 451-457. doi: https://doi.org/10.1016/j.cmi.2020.10.021.

Shamsizadeh, Z., Nikaeen, M., Nasr Esfahani, B., Mirhoseini, S. H., Hatamzadeh, M., \& Hassanzadeh, A. (2017). Detection of antibiotic resistant Acinetobacter baumannii in various hospital environments: potential sources for transmission of Acinetobacter infections. Environmental Health and Preventive Medicine, 22(1), 44. https://doi.org/10.1186/s12199-017-0653-4

Shinohara, D. R., Dos Santos Saalfeld, S. M., Martinez, H. V., Altafini, D. D., Costa, B. B., Fedrigo, N. H., \& Tognim, M. (2021). Outbreak of endemic carbapenem-resistant Acinetobacter baumannii in a coronavirus disease 2019 (COVID-19)-specific intensive care unit. Infection Control and Hospital Epidemiology, 1-3. https://doi.org/10.1017/ice.2021.98

Vaughn, V. M., Gandhi, T. N., Petty, L. A., Patel, P. K., Prescott, H. C., Malani, A. N., Ratz, D., McLaughlin, E., Chopra, V., \& Flanders, S. A. (2021). Empiric Antibacterial Therapy and Community-onset Bacterial Coinfection in Patients Hospitalized With Coronavirus Disease 2019 (COVID-19): A Multihospital Cohort Study. Clinical infectious diseases: an official publication of the Infectious Diseases Society of America, 72(10), e533-e541. https://doi.org/10.1093/cid/ciaa1239

Vázquez-López, R., Solano-Gálvez, S. G., Juárez Vignon-Whaley, J. J., Abello Vaamonde, J. A., Padró Alonzo, L. A., Rivera Reséndiz, A., Muleiro Álvarez, M., Vega López, E. N., Franyuti-Kelly, G., Álvarez-Hernández, D. A., Moncaleano Guzmán, V., Juárez Bañuelos, J. E., Marcos Felix, J., González Barrios, J. A., \& Barrientos Fortes, T. (2020). Acinetobacter baumannii Resistance: A Real Challenge for Clinicians. Antibiotics (Basel, Switzerland), 9(4), 205. https://doi.org/10.3390/antibiotics9040205 